\title{
Frequency of the acquired resistant mutation T790 M in non-small cell lung cancer patients with active exon 19Del and exon 21 L858R: a systematic review and meta-analysis
}

\author{
Zan-Feng Wang ${ }^{1 *}$, Sheng-Xiang Ren², Wei Li ${ }^{2}$ and Guang-Hui Gao ${ }^{2}$
}

\begin{abstract}
Background: Although EGFR-TKI is the preferred treatment for NSCLC patients with sensitive mutations, subsequent drug resistance is almost inevitable. The specific mechanisms of EGFR-TKI drug resistance can be identified through repeat biopsy.
\end{abstract}

Methods: To better understand the clinical characteristics of TKI resistance in NSCLC patients, we retrospectively reviewed studies of acquired TKI drug resistance using repeat biopsy from the last decade. The relevant literature was retrieved from January 2005 to August 2015 in the databases Medline and Embase. The search terms were NSCLC or non-small cell lung cancer and T790 M.

Results: A total of 478 patients with NSCLC tested by repeated biopsy were confirmed to have acquired TKI resistance. Analysis indicated that 240 patients (50.21\%) of the 478 patients with acquired TKI drug resistance had the T790 M mutation. The detection rate of T790 M in different repeat biopsy sites was also different, with the highest positive rate in the lymph nodes (60\%) and the lowest detection rate in cerebrospinal fluid (less than 5\%). In addition, patients with T790 M had longer overall survival compared to those without the mutation $(P<0.05)$. Of the 240 patients with T790 M mutations, 213 patients showed results consistent with the mutation analysis before TKI treatment, and the rate of patients with the L858R point mutation along with the T790 M mutation was lower than that of patients with the exon 19 deletion (36.42\% to 58.30\%).

Conclusions: $T 790 \mathrm{M}$ occurred more frequently in patients with the exon 19 deletion than in those with exon 21 L858R, which gave the survival benefit of the T790 M mutation and may explain why patients with the exon 19 deletion had an improved overall survival.

Keywords: Non-small cell lung cancer, Epidermal growth factor receptor,T790 M, Re-biopsy, Meta-analysis

\footnotetext{
* Correspondence: zanfengwang@163.com

'Department of Respiratory Medicine, The First Affiliated Hospital of China

Medical University, Shenyang, Liaoning, China

Full list of author information is available at the end of the article
} 


\section{Background}

Studies over the last decade [1-4] have demonstrated that somatic activating mutations in the tyrosine kinase domain of epidermal growth factor receptor (EGFR), including deletions in exon 19 (del19) and point mutations in exon 21 (L858R), are important mediators of cancer cell oncogenesis, proliferation and survival. Discovery of the EGFR-targeting agents gefitinib and erlotinib has provided significant insights into the biologic behaviors of non-small cell lung cancer (NSCLC). Gefitinib and erlotinib are firstgeneration EGFR-tyrosine kinase inhibitors (TKIs), and both agents play key roles in the treatment of EGFR-mutated NSCLC. However, the median progression-free survival (PFS) for NSCLC patients treated with gefitinib or erlotinib was only 10-12 months. L858R EGFR mutations in patients process less benefit, indicating that EGFR del19-positive disease may be different from those with L858R-positive [5]. Although the initial response to EGFR-TKIs is similar in NSCLC patients with del19 and point mutations in exon 21 (L858R), PFS and OS are significantly greater in patients with del19 than L858R [6-8]. The reason for this difference is currently unknown. Studies investigating repeat biopsies from patients with NSCLC who acquired resistance to erlotinib or gefitinib have demonstrated that the primary cause of drug resistance is the development of drug resistance mutations. Because these mutations substantially impact disease progression in patients with NSCLC, the prognostic difference between EGFR-TKI-treated patients with del19 and L858R might be attributable to differences in the mechanisms underlying drug resistance.

Data obtained from repeat biopsies revealed that the most common drug resistance mutation in patients with NSCLC is a point mutation in EGFR that results in the substitution of threonine with methionine at amino acid position 790 (T790 M) [9]. However, the sample size was too small to examine differences in outcomes between del19 and exon 21 L858R mutations. We conducted a systematic review of repeat biopsy studies in patients with NSCLC who developed resistance to EGFR-TKIs, so as to determine if there was a difference in the incidence of the T790 M EGFR mutation between patients with deletions in exon 19 and point mutations in exon 21 (L858R). In addition, we investigated the association of the T790 M mutation with clinicopathological features of patients with NSCLC.

\section{Methods}

\section{Study design and search strategy}

We searched the PubMed, Medline and Embase databases for relevant articles published before or on August 2015. We conducted a systematic review of articles published between January 2005 and August 2015 using the
Medline and Embase databases using the following search terms: NSCLC and T790 M. We only selected articles published in English. Case studies, letters, reviews and editorials were excluded from the analysis. Articles were required to meet the following criteria for inclusion in the meta-analysis: 1) the patients in the study had histologically verified NSCLC, and these patients were confirmed to have a clear EGFR-TKI-sensitive mutation by Droplet Digital Polymerase Chain Reaction (DDPCR) sequencing and 2) the patients underwent treatment with a first-generation EGFR-TKI (primarily gefitinib and erlotinib) and had undergone a repeat biopsy to test for drug resistance mutations because their disease had progressed despite an initial effective response to therapy.

\section{Selection of trials}

A total of 16 articles met the inclusion criteria and were selected for further analysis (Fig. 1). Data in 4 of the 16 studies originated from the same source (primarily Memorial Sloan-Kettering Cancer Center, Weill Medical College of Cornell University, NY, USA). The article that included the most patients and provided the most information was selected for further analysis to avoid redundancy. Two studies exclusively included patients from the University of Occupational and Environmental Health (Kitakyushu, Japan); therefore, only one of the two studies was retained for analysis. Another study was excluded because it included only 6 patients and did not report EGFR mutation status after the occurrence of drug resistance. A total of 10 clinical studies [10-19] were ultimately included in this systematic review.

\section{Data extraction and analysis}

The 10 studies included a total of 478 patients with NSCLC, pathologically confirmed EGFR-sensitizing mutations, and repeated biopsy to test drug resistance mutations after TKI treatment. The clinical characteristics of patients, including age, sex, smoking status, type of EGFR mutations, repeated biopsy specimens and OS sources, are shown in Table 1. Two reviewers independently assessed the eligibility of the studies identified by the search. We used Stata 11 software to analyze all data and assessed publication bias by Begg's Test. The heterogeneity was assessed using the Cochran $\mathrm{Q}$ test, and statistically significant heterogeneity was defined as $P<0.10$ and $\mathrm{I}^{2}>50 \%$. We used the random effects model of the Mantel-Haenszel method to calculate hazard ratio (HR) and 95\% confidence interval $(\mathrm{CI})$. In addition to the heterogeneity test, the difference was statistically significant at $P<0.05$. Due to the lack of detailed OS data for all patients, we were unable to perform a median test. Thus, we compared the operating systems between groups after the 


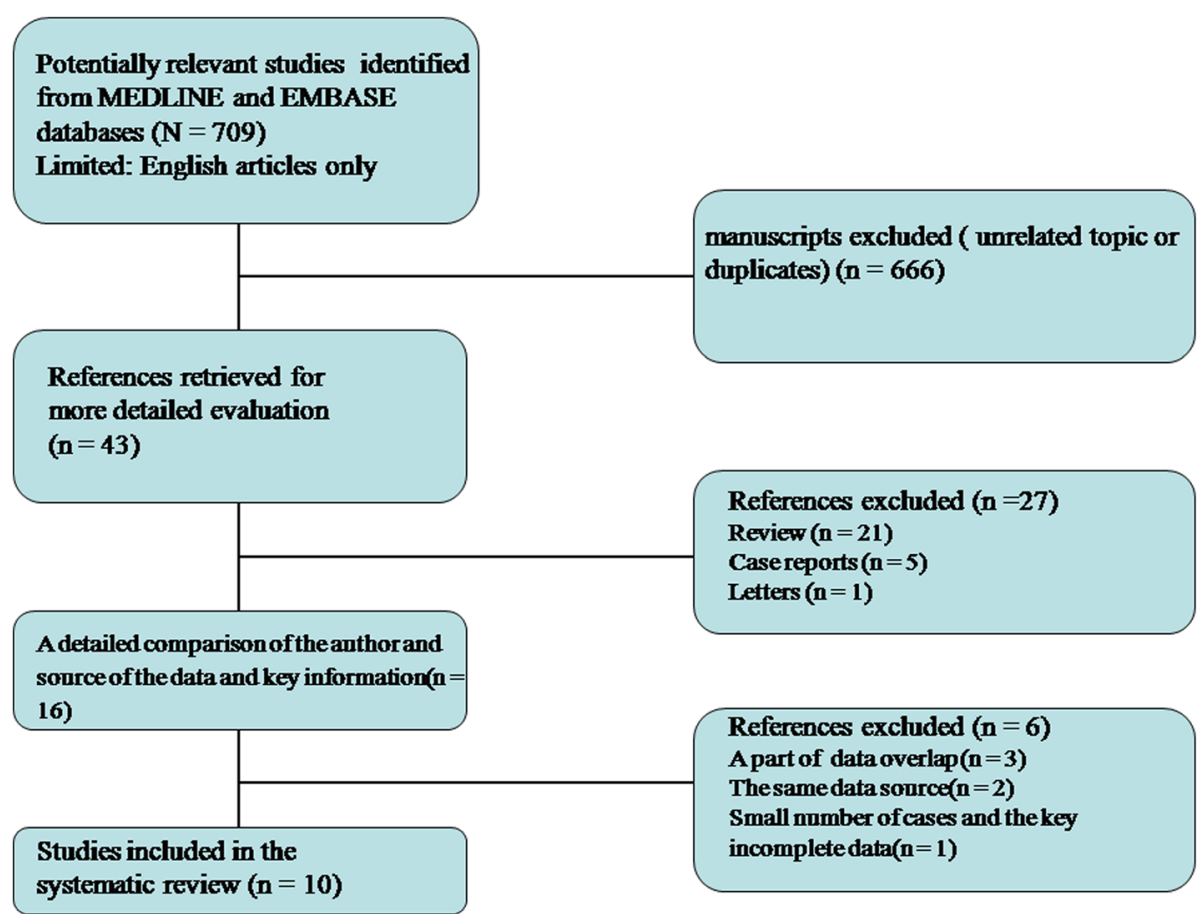

Fig. 1 Flowchart of this study

median was converted to the means as described by Hozo et al. [20]

\section{Results}

We analyzed potential mechanisms mediating drug resistance in 478 patients with NSCLC who acquired EGFR-TKI resistance and had undergone repeat biopsies. A total of 240 patients (50.21\%) presented the T790 M mutation. Among the 141 patients who were tested for MET amplification, 14 (9.93\%) tested positive. Eight (6.20\%) of the 129 patients with NSCLC exhibited histological transformation to SCLC. In addition, some patients presented with rare causes of drug resistance, including PIK3CA, HGF overexpression and HER2 amplification. However, the incidence of these cases was too low to conduct an independent analysis (Fig. 2).

Table 1 Study characteristics

\begin{tabular}{|c|c|c|c|c|c|c|}
\hline study & $\begin{array}{l}\text { No. of } \\
\text { patients }\end{array}$ & $\begin{array}{l}\text { Gender } \\
\mathrm{M} / \mathrm{F}\end{array}$ & $\begin{array}{l}\text { Age }(<70 / \\
\geq 70)\end{array}$ & $\begin{array}{l}\text { Smoking status } \\
(\mathrm{C} \text { or } \mathrm{F} / \mathrm{N})\end{array}$ & Treatment & $\begin{array}{l}\text { Detecting Items for Drug-Resistance } \\
\text { Mechanism }\end{array}$ \\
\hline Uramoto H et al. [10] & 11 & $3 / 8$ & $7 / 4$ & $2 / 9$ & gefitinib & $\begin{array}{l}\text { T790 M, KRAS,PTEN MET amp, } \\
\text { HGF status }\end{array}$ \\
\hline Kuiper JL et al. [11] & 66 & $14 / 52$ & NA & $30 / 33^{a}$ & erlotinib gefitinib & T790 M, SCLC, KRAS \\
\hline Sun JM et al. [12] & 70 & $18 / 52$ & NA & $14 / 56$ & erlotinib gefitinib & T790 M \\
\hline Li W et al. [13] & 54 & $29 / 25$ & $49 / 5$ & $7 / 47$ & erlotinib gefitinib Icotinib & T790 M \\
\hline Sequist LV et al. [14] & 37 & $15 / 22$ & $31 / 6$ & NA & erlotinib gefitinib & $\begin{array}{l}\text { T790 M, MET amp, SCLC, PIK3CA, } \\
\text { EMT }\end{array}$ \\
\hline Kosaka T et al. [15] & 14 & $4 / 10$ & NA & $6 / 8$ & Gefitinib & T790 M, KRAS \\
\hline Oxnard GR et al. [16] & 93 & $33 / 60$ & NA & $32 / 61$ & erlotinib gefitinib & T790 M, MET amp, HER2 \\
\hline Hata A et al. [17] & 78 & $24 / 54$ & $51 / 27$ & $24 / 54$ & erlotinib gefitinib & T790 M \\
\hline Chen HJ et al. [18] & 29 & $18 / 11$ & $27 / 2$ & $6 / 23$ & erlotinib gefitinib & T790 M, MET amp \\
\hline Ji W et al. [19] & 26 & $10 / 16$ & $21 / 5$ & NA & gefitinib & $\begin{array}{l}\text { T790 M, MET amp, AXL, EMT, } \\
\text { CD56 }\end{array}$ \\
\hline
\end{tabular}

ancertain for the 3 cases; $\mathrm{C}$ or $\mathrm{F} / \mathrm{N}=$ current or former /never smoker 


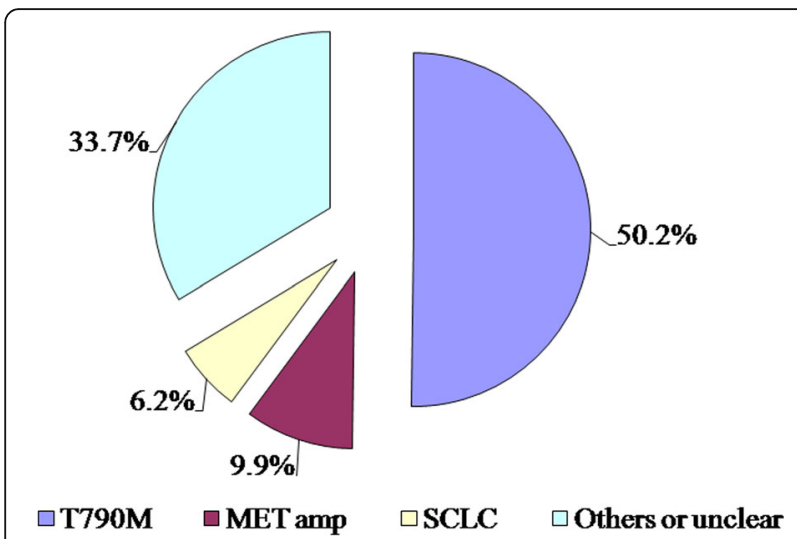

Fig. 2 The relative frequencies of the various mechanisms of acquired resistance

There was no significant difference in gender, age, or smoking habits between T790 M-positive and T790 M-negative patients. However, OS was significantly greater in T790 M-positive patients compared with T790 M-negative patients (Table 2).

The T790 M mutation was detected in 21 (60.0\%) of the 35 repeat lymph node biopsy specimens and in 129 (53.5\%) of the 241 lung and pleural biopsy specimens. As the number of single solid organ biopsy samples (including the skin, liver, brain, adrenal gland and bone) was small, it was difficult to conduct an independent analysis of these samples. The overall rate of T790 M mutation in the solid organ biopsies was 52.7\% (39/74), similar to that observed in lung and pleural biopsy samples. The rate in pleural effusion specimens was $45.5 \%$ (15/33). The T790 M mutation was detected in less than $5 \%$ of cerebrospinal fluid specimens $(1 / 21)$, which was significantly lower than that in other types of specimens $(P<0.05)$ (Fig. 3).

In 240 T790 M-positive NSCLC patients, 27 patients had secondary biopsy results inconsistent with the initial results; as this may be related to the temporal heterogeneity of the organization and spatial heterogeneity, these findings were not included in the comparison. The remaining 213 patients had sensitive mutations (55 patients with the exon 21 L858R point mutation and 158 patients with the del19 mutation). The 55 T790 M-positive patients with the L858R mutation accounted for $36.42 \%$ of total patients with L858R, and the 158 T790 M-positive

Table 2 Clinical Characteristics

\begin{tabular}{|c|c|c|c|c|c|c|c|}
\hline & \multicolumn{2}{|c|}{ Gender(n) } & \multicolumn{2}{|c|}{ Age(n) } & \multicolumn{2}{|c|}{ Smoking status(n) } & \multirow{2}{*}{$\begin{array}{l}\text { OS* } \\
\text { (months) }\end{array}$} \\
\hline & Man & Female & $<70$ & $\geq 70$ & Smoker & Non-smoker & \\
\hline T790 M(+) & 73 & 133 & 84 & 22 & 46 & 136 & 41.6 \\
\hline T790 M(-) & 81 & 125 & 102 & 27 & 45 & 127 & 30.3 \\
\hline
\end{tabular}

${ }^{*} P<0.05$ (data from the research11, 12, 13, 16 and19; $n=309$ )

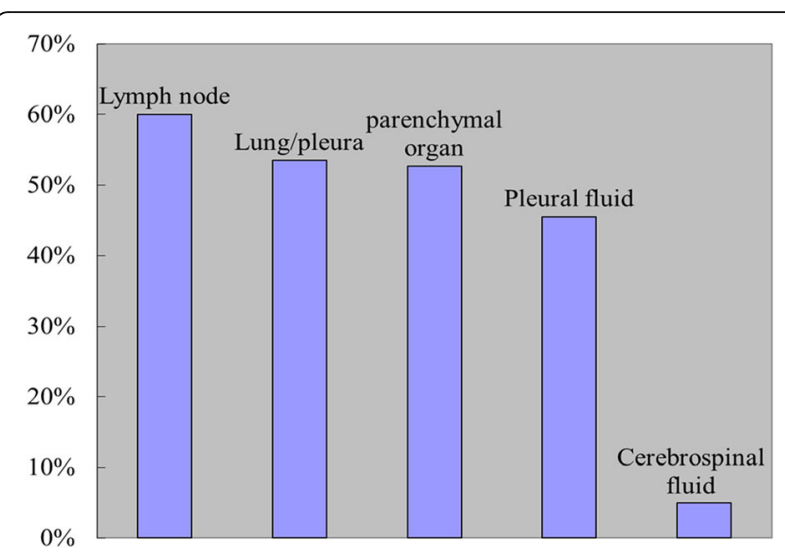

Fig. 3 The positive rate of T790 M at different biopsy parts

patients with the del19 mutation accounted for $58.30 \%$ of total patients with del19 $(36.42 \%$ vs $58.30 \%, P<0.01)$. The meta-analysis also revealed that the prevalence of the T790 M mutation was significantly greater in patients with the del19 mutation compared with the L858R mutation (HR: 2.34, 95\% CI: 1.54-3.54, $P<0.05$, Begg's Test $\operatorname{Pr}>|\mathrm{Z}|=0.048$ ) (Fig. 4).

\section{Discussion}

$\mathrm{D}$ Ross et al. reviewed the acquired resistance to EGFR TKI in lung cancer and found that the second EGFR mutation comprised approximately 60\% (the T790 M mutation was approximately $40-55 \%$ ), the bypass activation mutation was approximately 20\% (Met amplification 5\%, HER2 amplification 8-13\%, Sclc 10\%, BRAF 1\%, PIk3CA $1-2 \%$ and EMT 1-2\%), and other unknown mechanisms accounted for $15-20 \%$ [21]. The incidence of T790 M mutations in patients with NSCLC was between 33\% and $60 \%$ in the previous study, and these differences were predominantly attributable to differences in the detection method and sample size. The primary cause of acquired resistance to TKIs in patients with NSCLC is the T790 M mutation, followed by MET amplification and SCLC transformation. The 10 studies included in the present metaanalysis used different methods, which might have had differing sensitivities for detecting the T790 M mutation. However, as all studies used common clinical testing methods, the observed incidence of T790 M (50.21\%) might be clinically relevant. Several new agents that target T790 M, including AZD9291 and HM61713, are being investigated in phase III trials of NSCLC patients with EGFR mutations and T790 M-mediated TKI resistance. These agents have shown extremely promising results, and AZD9291 has been approved by the US Food and Drug Administration [22, 23]. Given the complexity of the various mechanisms underlying EGFR-TKI resistance, repeat biopsies are required to clarify the precise mechanism underlying this phenomenon in patients with NSCLC. 


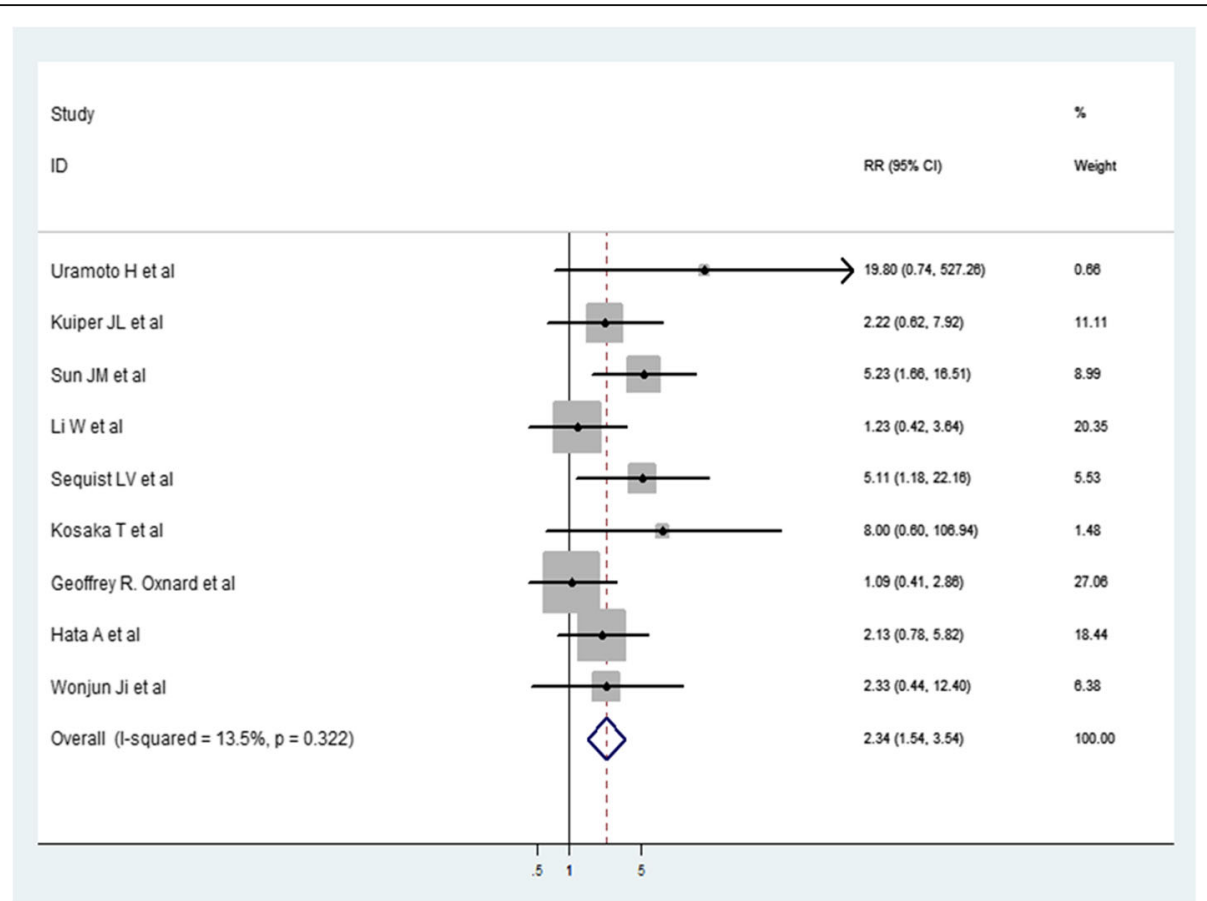

Fig. 4 Meta-analysis about positive ratio of acquired T790 M mutation in patients withexon19 deletion and L858R point mutation. (One study [18] cannot be included due to not providing the type of mutation with initial biopsy)

Patients with the T790 M mutation, irrespective of EGFR activating mutation subtypes, had better survival beyond EGFR-TKI progression, which suggested that resistance acquired through the T790 M mutation might follow a more indolent course than clinical resistance without the mutation. Several clinical studies [16, 17, 24] reported similar results in Caucasian population and East-Asia population, respectively. Notably, preclinical data have also demonstrated that acquisition of the T790 M mutation is associated with more indolent growth than in parental cell lines without T790 M mutation in the absence of TKI selection [25]. The results have validated previous findings and further elucidated the association between T790 M-independent mechanisms and the better survival of patients with del19.

Patients with del19 treated with first-generation TKIs showed a greater clinical benefit than that of patients with L858R mutations [24, 26]. Yang et al. reported differences in prognosis among NSCLS patients with different sensitive mutations who underwent afatinib treatment. Drug resistance is the most important factor affecting the disease process, and the T790 M mutation is the most common drug resistance mechanism. To eliminate the limitation of inadequate sample size and confirm these findings, we conducted a systematic review of studies published over the past 10 years and found that patients with del19 had a higher incidence of
T790 M mutation compared to patients with L858R (58.30\% vs $36.42 \%)$.

Exon 19 deletion mutations are more likely to develop T790 M mutations, and T790 M mutant cell lines proliferate slowly [26], which may be one of the possible mechanisms for the improved prognosis of patients with del19 after TKI treatment. T790 M mutation patients are more likely to receive effective follow-up treatment, which may also extend the OS of NSCLC patients with del19.

We also analyzed the association of the T790 M mutation with the clinicopathological features of NSCLC patients. The prevalence of the T790 M mutation varied according to the sites of the repeat biopsy, with the highest rate observed in metastatic lymph nodes biopsies (60\%), followed by lung and pleural biopsies (53.5\%), biopsies from other parenchymatous organs (52.7\%) and pleural effusion biopsies (45.5\%). Although these differences were not statistically significant, they deserve attention because pleural effusion is one of the most common biopsy sites in patients with NSCLC. In addition, the observation that OS was increased in T790 M-positive patients indicates that T790 M might be a useful marker for predicting the prognosis of NSCLC patients who underwent TKI therapy.

Of note, there are several limitations in our study. First, none of the studies included in the analysis were randomized controlled studies, the number of studies 
was small, and some sample size were too small, those might cause possible result publication bias. Second, although the T790 M mutation accounts for $50 \%$ of cases of acquired TKI resistance, the other mechanisms mediating acquired resistance were not examined in this study. Third, unfortunately, we did not include one study that evaluated a large number of repeat biopsies [9] because the authors did not report the type of sensitizing mutations in patients with NSCLC with the T790 M mutation. Therefore, we had to include another study from the same research center [16].

As the T790 M mutation is associated with improvements in OS in patients with NSCLC, it might serve as a prognostic factor. The higher incidence of the T790 M mutation in patients with del19 compared with exon 21 L858R might account for the higher OS rate observed in patients with del19; however, this hypothesis deserves further investigation.

\section{Conclusions}

The T790 M mutation is the primary cause of EGFR-TKI resistance. Considering the survival benefit of the T790 M mutation and the finding that T790 M occurred more frequently in patients with del19 than those with exon 21 L858R, this may explain why the patients with del19 had an improved OS.

\section{Abbreviations}

Cl: Confidence interval; DDPCR: Droplet Digital Polymerase Chain Reaction; EGFR: Epidermal growth factor receptor; HR: Hazard ratio; NSCLC: Non-small cell lung cancer; OS: Overall survival; PFS: Progression-free survival; T790 M: The substitution of threonine with methionine at amino acid position 790; TKIs: Tyrosine kinase inhibitors

\section{Acknowledgements}

Not applicable.

\section{Funding}

No

\section{Availability of data and materials}

The dataset supporting the conclusions of this article is available on request from the authors.

\section{Authors' contributions}

WZF was the primary author of this manuscript, and he and RSX co-directed the study, including the study design and data analysis. WZF and RSX conducted the focus groups. LW and GGH made substantial contributions to the study design, data interpretation, and resulting manuscript. All authors provided input on multiple drafts of the manuscript and approval of the final draft.

\section{Ethics approval and consent to participate}

Not applicable.

\section{Consent for publication}

Not applicable.

\section{Competing interests}

The authors declare that they have no competing interests.

\section{Publisher's Note}

Springer Nature remains neutral with regard to jurisdictional claims in published maps and institutional affiliations.

\section{Author details}

'Department of Respiratory Medicine, The First Affiliated Hospital of China Medical University, Shenyang, Liaoning, China. ${ }^{2}$ Department of Medical Oncology, Shanghai Pulmonary Hospital,Tongji University, Tongji University Medical School Cancer Institute, Shanghai, China.

Received: 4 November 2016 Accepted: 29 January 2018

Published online: 06 February 2018

\section{References}

1. Mitsudomi T, Morita S, Yatabe Y, Negero S, Okamtot I, Tsurutani J, Seto T, Satouchi M, Tada H, Hirashima T, et al. Cancer harbouring mutations of the epidermal growth factor receptor (WJTOG3405): an open label, randomised phase 3 trial. Lancet Oncol. 2010;11:121-8.

2. Maemondo M, Inoue A, Kobayashi K, Sugawara S, Oizumi S, Isobe H, Gemma A, Harade M, Yoshizawa H, Kinoshita I, et al. Gefitinib or chemotherapy for non-small-cell lung cancer with mutated EGFR. N Engl J Med. 2010;362:2380-8.

3. Zhou C, Wu YL, Chen G, Feng J, Liu XQ, Wang C, Zhang S, Wang J, Zhou S, Ren $\mathrm{S}$, et al. Erlotinib versus chemotherapy as first-line treatment for patients with advanced EGFR mutation-positive non-small-cell lung cancer (OPTIMAL, CTONG-0802): a multicentre, openlabel, randomised, phase 3 study. Lancet Oncol. 2011;12:735-42.

4. Rosell R, Carcereny E, Gervais R, Vergnenegre A, Massuti B, Felip E, Palmero R, Garcia-Gomez R, Pallares C, Sanchez JM, et al. Erlotinib versus standard chemotherapy as first-line treatment for European patients with advanced EGFR mutation-positive non-small-cell lung cancer (EURTAC): a multicentre, open-label, randomised phase 3 trial. The Lancet Oncology. 2012;13:239-46.

5. Yang JC, Wu YL, Schuler M, Sebastian M, Popat S, Yamamoto N, Zhou C, Hu CP, O'Byrne K, Feng J, et al. fatinib versus cisplatin-based chemotherapy for EGFR mutation-positive lung adenocarcinoma (LUX-lung 3 and LUX-lung 6): analysis of overall survival data from two randomised, phase 3 trials. Lancet Oncol. 2015;16:141-51

6. Lee VH, Tin VP, Choy TS, Lam KO, Choi CW, Chung LP, Tsang JW, Ho PP, Leung DK, Ma ES, et al. Association of Exon 19 and 21 EGFR mutation patterns with treatment outcome after first-line tyrosine kinase inhibitor in metastatic nonsmall-cell lung cancer. The Lancet Oncology. 2013;8:1148-55.

7. Jackman DM, Yeap BY, Sequist LV, Lindeman N, Holmes AJ, Joshi VA, Bell DW, Huberman MS, Halmos B, Rabin MS, et al. Exon 19 deletion mutations of epidermal growth factor receptor are associated with prolonged survival in non-small cell lung cancer patients treated with gefitinib or erlotinib. Clin Cancer Res. 2006;12:3908-14.

8. Riely GJ, Pao W, Pham D, Li AR, Rizvi N, Venkatraman ES, Zakowski MF, Kris MG, Ladanyi M, Miller VA. Clinical course of patients with non-small cell lung cancer and epidermal growth factor receptor exon 19 and exon 21 mutations treated with gefitinib or erlotinib. Clin Cancer Res. 2006;12:839-44.

9. Yu HA, Arcila ME, Rekhtman N, Sima CS, Zakowski MF, Pao W, Kris MG, Miller VA, Ladanyi M, Riely GJ. Analysis of tumor specimens at the time of acquired resistance to EGFR-TKI therapy in 155 patients with EGFR-mutant lung cancers. Clin Cancer Res. 2013;19:2240-7.

10. Uramoto H, Yano S, Tanaka F. T790M is associated with a favorable prognosis in Japanese patients treated with an EGFR-TKI. Lung Cancer. 2012;76:129-30

11. Kuiper UL, Heideman DA, Thunnissen E, Paul MA, van Wijk AW, Postmus PE, Smit EF. Incidence of T790M mutation in (sequential) rebiopsies in EGFRmutated NSCLC-patients. Lung Cancer. 2014;85:19-24.

12. Sun JM, Ahn MJ, Choi YL, Ahn JS, Park K. Clinical implications of T790M mutation in patients with acquired resistance to EGFR tyrosine kinase inhibitors. Lung Cancer. 2013;82:294-8.

13. Li W, Ren S, Li J, Li A, Fan L, Li X, Zhao C, He Y, Gao G, Chen X, et al. T790M mutation is associated with better efficacy of treatment beyond progression with EGFR-TKI in advanced NSCLC patients. Lung Cancer. 2014;84:295-300.

14. Sequist $L V$, Waltman BA, Dias-Santagata D, Digumarthy $S$, Turke AB, Fidias $P$, Bergethon K, Shaw AT, Gettinger S, Cosper AK, et al. Genotypic and histological evolution of lung cancers acquiring resistance to EGFR inhibitors. Sci Transl Med. 2011;3:75ra26. 
15. Kosaka T, Yatabe Y, Endoh H, Yoshida K, Hida T, Tsuboi M, Tada H, Kuwano $\mathrm{H}$, Mitsudomi T. Analysis of epidermal growth factor receptor gene mutation in patients with non-small cell lung cancer and acquired resistance to Gefitinib. Clin Cancer Res. 2006:12:5764-9.

16. Oxnard GR, Arcila ME, Sima CS, Riely GJ, Chmielecki J, Kris MG, Pao W, Ladanyi M, Miller VA. Acquired resistance to EGFR tyrosine kinase inhibitors in EGFR mutant lung cancer: distinct natural history of patients with tumors harboring the T790M mutation. Clin Cancer Res. 2011;17:1616-22.

17. Hata A, Katakami N, Yoshioka H, Takeshita J, Tanaka K, Nanjo S, Fujita S, Kaji R, Imai Y, Monden K, et al. Rebiopsy of non-small cell lung cancer patients with acquired resistance to epidermal growth factor receptor-tyrosine kinase inhibitor: comparison between T790M mutation-positive and mutation-negative populations. Cancer. 2013;119:4325-32.

18. Chen HJ, Mok TS, Chen ZH, Guo AL, Zhang XC, Su J, Wu YL. Clinicopathologic and molecular features of epidermal growth factor receptor T790M mutation and c-MET amplification in tyrosine kinase inhibitor- resistant Chinese non-small cell lung cancer. Pathol Oncol Res. 2009;15:651-8

19. Ji W, Choi CM, Rho JK, Jang SJ, Park YS, Chun SM, Kim WS, Lee JS, Kim SW, Lee $\mathrm{DH}$, et al. Mechanisms of acquired resistance to EGFR-tyrosine kinase inhibitor in Korean patients with lung cancer. BMC Cancer. 2013;13:606.

20. Hozo SP, Djulbegovic B, Hozo I. Estimating the mean and variance from the median, range, and the size of a sample. BMC Med Res Methodol. 2005;5:13.

21. Ross Camidge D, Pao W, Lecia V. Sequist:acquired resistance to TKls in solid tumours: learning from lung cancer. Nature reviews Clin Oncol. 2014;11:473-81.

22. Janne PA, Yang JC, Kim DW, Planchard D, Ohe Y, Ramalingam SS, Ahn MJ, Kim SW, Su WC, Horn L, Haggstrom D, Felip E, Kim JH, et al. AZD9291 in EGFR inhibitor-resistant non-small-cell lung cancer. N Engl J Med. 2015;372:1689-99.

23. Kim DW, Lee DH, Kang JH, Park K, Han JY, Lee JS, Jang IJ, Kim HY, Son J, Kim JH. Clinical activity and safety of HM61713, an EGFRmutant selective inhibitor, in advanced non-small cell lung cancer (NSCLC) patients (pts) with EGFR mutations who had received EGFR tyrosine kinase inhibitors (TKIs). J Clin Oncol. 2014:32:55

24. Kim DW, Lee SH, Lee JS, et al. A multicenter phase ii study to evaluate the efficacy and safety of gefitinib as first-line treatment for Korean patients with advanced pulmonary adenocarcinoma harboring EGFR mutations. Lung Cancer. 2011;71:65-9.

25. Chmielecki J, Foo J, Oxnard GR, Hutchinson K, Ohashi K, Somwar R, Wang L, Amato KR, Arcila M, Sos ML, et al. Optimization of dosing for EGFR mutant non-small cell lung cancer with evolutionary cancer modeling. Sci Transl Med. 2011;3:90ra59.

26. Rosell R, Moran T, Queralt C, Porta R, Cardenal F, Camps C, Majem M, LopezVivanco G, Isla D, Provencio $M$, et al. Screening for epidermal growth factor receptor mutations in lung cancer. N Engl J Med. 2009;361:958-67.

\section{Submit your next manuscript to BioMed Central and we will help you at every step:}

- We accept pre-submission inquiries

- Our selector tool helps you to find the most relevant journal

- We provide round the clock customer support

- Convenient online submission

- Thorough peer review

- Inclusion in PubMed and all major indexing services

- Maximum visibility for your research

Submit your manuscript at www.biomedcentral.com/submit

) Biomed Central 